Ernst Roidl, Felix Wilhelm Siebert, Michael Oehl, Rainer Höger

\title{
Introducing a multivariate model for predicting driving performance: The role of driving anger and personal characteristics
}

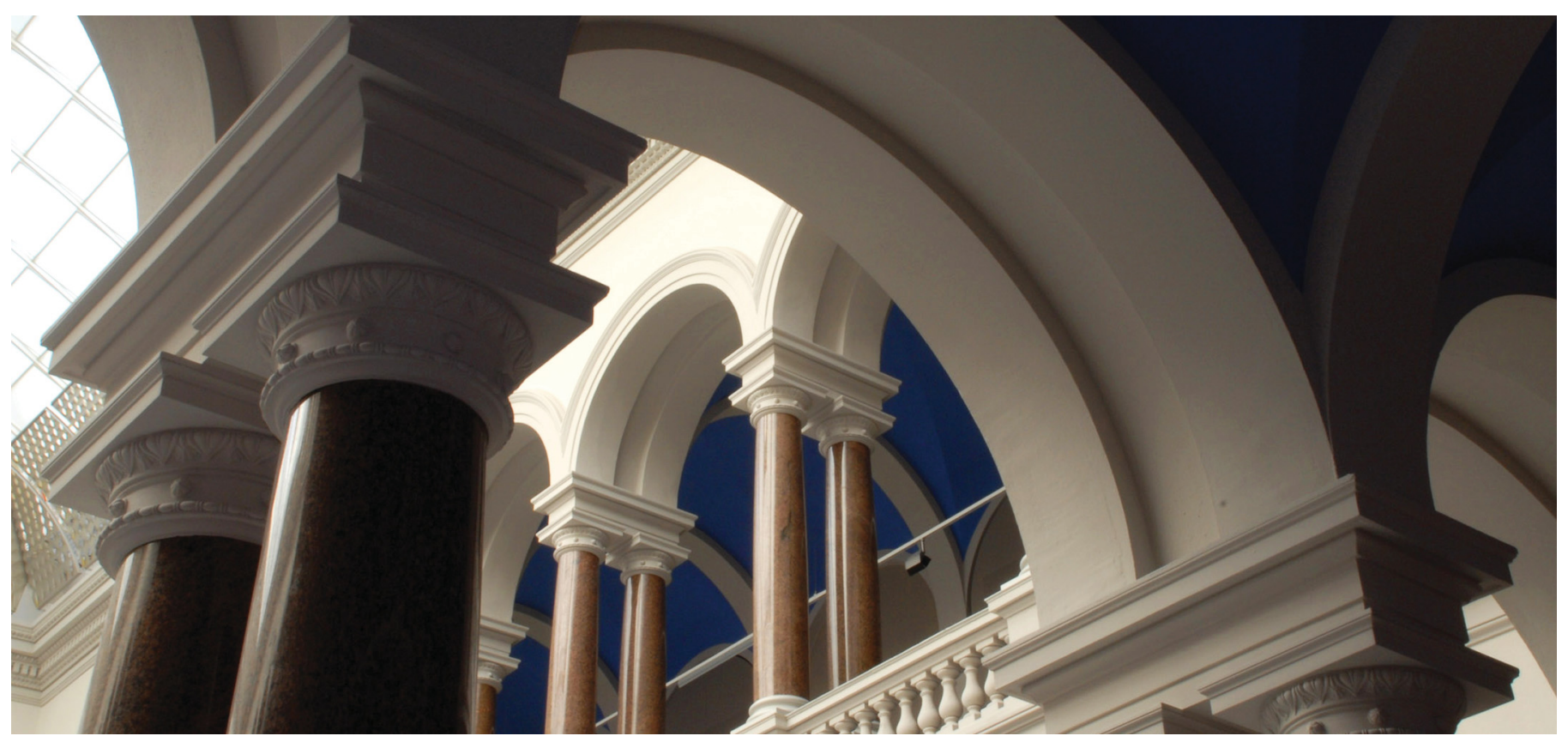

Roidl, E., Siebert, F. W., Oehl, M., Höger, R. (2013). Introducing a multivariate model for predicting driving performance: The role of driving anger and personal characteristics. Journal of Safety Research, 47, 47-56. https://doi.org/10.1016/j.jsr.2013.08.002 
This is the Accepted Manuscript of the following article published by Elsevier in Journal of Safety Research [15. August 2013]:

Roidl, E., Siebert, F. W., Oehl, M., \& Höger, R. (2013). Introducing a multivariate model for predicting driving performance: The role of driving anger and personal characteristics. Journal of safety research, 47, 47-56. https://doi.org/10.1016/j.jsr.2013.08.002 This manuscript is not the copy of record and may not exactly replicate the final, authoritative version of the article.

This work is licensed under a Creative Commons Attribution-NonCommercial-NoDerivatives 4.0 International License, http://creativecommons.org/licenses/by-nc-nd/4.0/. 


\title{
Introducing a multivariate model for predicting driving performance: The role of driving anger and personal characteristics
}

\author{
Ernst Roidl*, Felix Wilhelm Siebert, Michael Oehl, Rainer Höger \\ * Corresponding author: roidl@leuphana.de
}

\begin{abstract}
Introduction: Maladaptive driving is an important source of self-inflicted accidents and this driving style could include high speeds, speeding violations, and poor lateral control of the vehicle. The literature suggests that certain groups of drivers, such as novice drivers, males, highly motivated drivers, and those who frequently experience anger in traffic, tend to exhibit more maladaptive driving patterns compared to other drivers. Remarkably, no coherent framework is currently available to describe the relationships and distinct influences of these factors.

Method: We conducted two studies with the aim of creating a multivariate model that combines the aforementioned factors, describes their relationships, and predicts driving performance more precisely. The studies employed different techniques to elicit emotion and different tracks designed to explore the driving behaviors of participants in potentially angerprovoking situations. Study 1 induced emotions with short film clips. Study 2 confronted the participants with potentially anger-inducing traffic situations during the simulated drive. Results: In both studies, participants who experienced high levels of anger drove faster and exhibited greater longitudinal and lateral acceleration. Furthermore, multiple linear regressions and path-models revealed that highly motivated male drivers displayed the same behavior independent of their emotional state. The results indicate that anger and specific risk characteristics lead to maladaptive changes in important driving parameters and that drivers with these specific risk factors are prone to experience more anger while driving, which further worsens their driving performance. Driver trainings and anger management courses will profit from these findings because they help to improve the validity of assessments of anger related driving behavior.
\end{abstract}

Keywords - emotions, driving anger, driving motivation, driving performance, risky driving 


\section{Introduction and theoretical background}

In recent years, driving at high speeds has become prevalent on streets worldwide (Deffenbacher, Deffenbacher, Lynch \& Richards, 2003; Paleti, Eluru and Bhat, 2010; Stradling \& Parker, 1997). The American Automobile Association found that speeding was responsible for $31 \%$ of incidents and was the most prevalent cause of fatal crashes between 2003 and 2007 (AAA Foundation for Traffic Safety, 2009). In Germany, almost 400,000 people were involved in traffic accidents in 2011, and approximately 4000 people died (Destatis, 2012); maladaptive speeds (e.g., speeding, or failing to adjust for bad weather or road conditions) were responsible for over $26 \%$ of vehicle crashes. The impact of high speeds on driving safety is manifold. For example, driving too fast can lead to decreased reaction times and to the loss of control over the car or to reductions in the distances from other traffic to below safe levels due to increased variation in speed across all traffic (Aarts \& Van Schagen, 2006). However, the currently available traffic studies normally do not provide any conclusions about the motivational or emotional states of the drivers, and speeding is usually described simply as an example of dangerous, risky, and/or aggressive driving behavior (AAA Foundation for Traffic Safety, 2009; NHTSA, 2008). The lack of information about driver states and the use of different wordings across studies may inhibit understanding, create communication problems between researchers, and slow the pace of progress in the traffic psychology domain (Dula \& Geller, 2003; Reason, Manstead, Stradling, Baxter \& Campbell, 1990).

Shinar (1998) defines two states of unsafe driving behavior. In the "cold"-state, drivers exhibit maladaptive driving behaviors, such as driving at high speeds or violating the speed limit in a risky but non-malicious way, to overcome obstacles and accomplish their goals without the intention of harming others. However, drivers in a "hot"-state are prone to behave aggressively toward other drivers (Shinar, 1998). Both states can involve tailgating, running red lights and cutting other drivers off, but only the latter state incorporates the clear intention to do harm (Dula \& Geller, 2003; Ellison-Potter, Bell \& Deffenbacher, 2001; Lajunen, Parker $\&$ Stradling, 1998). Dula and Geller (2003) suggested that the term dangerous driving be defined as a construct with three dimensions: risk-taking, negative emotions experienced while driving, and intentional acts of aggression toward others. Several correlations exist between these dimensions and their impacts on driving safety. Risk taking can include driving at high speeds, fast acceleration, and poor lateral control (Dula \& Ballard, 2003) and may be intensified by negative emotions such as anger and/or frustration (Stephens \& Groeger, 2009). The effect of negative emotions may be due to more perceived control and therefore more 
optimistic risk appraisal (Lerner \& Keltner, 2001). The influence of anger and risk-taking on higher speeds and increased acceleration in traffic has been shown in a series of studies (Deffenbacher et al., 2003; Matthews et al., 1998; Mesken, Hagenzieker, Rothengatter \& De Waard, 2007; Stephens \& Groeger, 2009). Aggressive actions while driving are also related to the emotions of frustration and/or anger and usually include intentionally aggressive actions directed toward other drivers including gestures, honking, and giving chase (Britt \& Garrity, 2006; Dula \& Ballard, 2003; Taubman-Ben-Ari, Mikulincer \& Gillath, 2004). Velocity, acceleration, lateral acceleration, and speeding were the focus of this study due to the relevance of these factors to emotional driving that has been documented in the literature (Cai \& Lin, 2011; Deffenbacher et al., 2003; Stephens \& Groeger, 2009).

Research suggests that driving-related anger is an important negative emotion that can increase risky driving behaviors such as driving high speeds and/or speeding (Björklund, 2008; Deffenbacher et al., 2003; Lajunen \& Parker, 2001; Nesbit, Conger \& Conger, 2007). However, other variables, such as driving experience, gender (Björklund, 2008; Dula \& Ballard, 2003; Ferguson, 2003; Laapotti \& Keskinen, 2004; Mesken, Lajunen \& Sumala, 2002) and driving motivation (Philippe, Vallerand, Richer, Vallières \& Bergeron, 2009), can also lead to similar driving patterns. There is little research employing empirically tested models that combine these variables to reveal the interactions and distinct impacts of personal characteristics, driving-related anger, and key indicators of safe driving performance. To create and validate such a model, we conducted two simulator studies. The core elements of our model are the following: (a) the impact of anger on potentially relevant driving parameters (velocity, speeding, longitudinal and lateral acceleration); (b) the influence of personal characteristics on the experience of anger experiences in traffic; and (c) the impact of personal characteristics on the driving parameters independent of anger. The following sections review the literature and discuss the key findings regarding these specific core components. The lack of research that examines the interactions of these elements emphasizes the necessity of a coherent model.

\section{Driving anger and risky driving}

Unlike emotional and hostile aggression in driving situations, which is fed by strong emotional states and focuses on harming other traffic participants, risky driving patterns often lack accompanying emotions or the intention to harm (Shinar, 1998). Nonetheless, studies indicate a consistent relationship between anger and specific risky driving behavior in traffic (e.g., Dahlen \& White, 2006; Deffenbacher et al., 2003). Most importantly, anger can produce 
increases in speed (Deffenbacher, Lynch, Oetting \& Yingling, 2001; Matthews et al., 1998; Underwood, Chapman, Wright \& Crundall, 1999), traffic violations (Maxwell, Grant \& Lipkin, 2005; Sümer, 2003) and more generic risky behavior such as driving recklessly or acting carelessly when other people are in the car (Deffenbacher et al., 2001). These behaviors can increase the risk of crashes and endanger other road participants (Chliaoutakis et al., 2002; Deffenbacher et al., 2003; Underwood et al., 1999). Generally, a moderate relationship exists between anger and risky driving, which is typically described with broad behaviors (e.g., reckless or drunk driving) and less often in terms of the specific driving patterns. Therefore, real driving and simulator studies are necessary to adequately assess driving parameters such as speed (Matthews et al., 1998; Mesken et al., 2007). Stephens and Groeger (2009) added means and standard deviations of longitudinal and lateral acceleration, lateral position, steering throttle and brake input to the predicted parameters. Those authors revealed a consistent relationship between high anger levels and increased values for most of those variables.

\section{Personal characteristics and driving anger}

To describe the factors that influence anger in traffic environments more precisely, the personal characteristics of the driver must to taken into account (Mesken, Lajunen \& Sumala, 2002). Driving experience, as measured in total or yearly mileage, is inconsistent as a predictor of anger and is strongly dependent on gender (Lajunen \& Parker, 2001). In a study by Björklund (2008), driving experience was found to influence drivers' anger levels in situations involving reckless driving or direct hostility toward others but only for female participants. In the male population, there was no effect of mileage on experienced anger (Björklund, 2008). The gender of the participants can influence anger-reactivity in various situations: men report more anger when they are impeded by other drivers (Deffenbacher, Oetting \& Lynch, 1994), and women are more angered when they are confronted with direct hostility, illegal actions by others, or traffic obstructions (Parker, Lajunen \& Sumala, 2002). Together, these findings seem to indicate a strong situational component in the relationship between anger, driving experience, and gender.

A more constant link exists between trait-related anger and 'state anger,' which is the actual anger experienced in traffic situations (Deffenbacher, Huff, Lynch, Oetting \& Salvatore, 2000; Deffenbacher et al., 2001). People show different tendencies to become angry in traffic, such as in frustrating or provoking situations (Deffenbacher et al., 2003). Subsequently, drivers with high trait anger experience more and intensified anger in such situations 
compared to drivers scoring low on trait anger (Deffenbacher et al., 2003; Spielberger, 1988). This disposition to become angry in traffic is a construct labeled trait-driving anger and is often measured with the driving anger scale (DAS, Deffenbacher et al., 1994).

Another important determinant of anger while driving is driving motivation. When driving begins to play a role in the personal identities of traffic participants and becomes an obsessive passion that controls their actions, it can lead to intensified driving behavior (Philippe et al., 2009; Vallerand, 2008). These highly motivated drivers tend to experience more intense and more frequent negative emotions such as anger in goal-blocking situations (e.g., impeded progress on the road or the erratic driving of others; Philippe et al., 2009).

Reviews of the big five factors (extraversion, neuroticism, consciousness, agreeableness, and openness) have revealed that sometimes neuroticism is related to anger in driving contexts, and emotionally unstable individuals report more intense anger in various traffic situations (Dahlen \& White, 2006).

\section{Personal characteristics and risky driving}

In addition to the relationship between personal characteristics and driving anger, some evidence indicates a direct influence of personal characteristics on risky driving patterns without driving anger (Fisher et al., 2002; Krahé \& Fenske, 2002; Reason et al., 1990). Males drive faster than females in traffic (De Winter et al., 2009; DeJoy, 1992; Shinar, Schechtman \& Compton, 2001), which may increase the frequency and severity of accidents. An important reason for this behavior is the differences in risk homeostasis levels between males and females, which increase risk taking behavior in males, which could in turn lead to higher speeds and more traffic violations in general (Deery \& Fildes, 1999; Laapotti \& Keskinen, 2004, Rosenbloom, Shahar, Elharar \& Danino, 2008). Furthermore, male drivers may overestimate their driving skills, which could lead to driving at higher speeds and increases in the frequency of involvement in motor vehicle accidents (Deery \& Fildes, 1999; DeJoy, 1992; Ulleberg, 2002; Yagil, 1998).

The findings surrounding the impact of driving experience on (maladaptive) driving performance are more complex. There is a consensus that constant exposure to traffic (operationalized as miles per year) shapes the mental models of drivers and improves their abilities to detect hazards (Brown \& Groeger, 1988; Deery \& Fildes, 1999; McKnight \& McKnight, 2000; Underwood, Chapman, Brocklehurst, Underwood \&Crundall, 2003) and assess risks, which leads to more adaptive driving behaviors (Ferguson, 2003; Groeger \& Chapman, 1996). Therefore, experienced drivers do not encounter as many critical situations 
per kilometer as compared to novice drivers, and experienced drivers react more appropriately if such situations arise (Underwood et al., 2003), which reduces the probability of crashing (Laapotti, Keskinen, Hatakka \& Katila, 2001). However, a better understanding of the traffic environment can lead to higher speeds and more traffic violations (Björklund, 2008; Laapotti \& Keskinen, 2004), which are risk factors for other traffic participants.

No previous research has explicitly addressed the relationship between driving performance and driving motivation with the exception of studies addressing aggressive behavior while driving (e.g., swearing and hostile gestures) due to intensified anger in individuals with an obsessive passion to drive (Philippe et al., 2009). However, some evidence shows that young males differ from older drivers and females in their motives and attitudes (Laapotti et al., 2001). For the latter population, driving is more instrumental (i.e., directed toward reaching a destination or toward transporting goods), whereas for young males, driving is a means to fulfill hedonic motives and to express and assert themselves; thus, males drive at higher speeds for pleasure and to gain admiration from their peers (Laapotti \& Keskinen, 2004).

Research on the big five personality factors has produced mixed findings regarding the relationships between the factors and driving outcomes and behavior. For example, extraversion and accidents have been found to be positively related (Lajunen, 2001; Martin \& Boomsma, 1989; Smith \& Kirkham, 1981), negatively (Pestonjee \& Singh, 1980), and unrelated in traffic contexts (Dahlen \& White, 2006). In the cases of neuroticism (Dahlen \& White, 2006; Pestonjee \& Singh, 1980) and openness (Arthur \& Graziano, 1996), most studies have found little or no correlation with total accidents. Nevertheless, some studies have supported the conclusion that consciousness (Arthur \& Doverspike, 2001; Arthur \& Graziano, 1996) and agreeableness (Cellar, Nelson \& Yorke, 2000) are factors that influence deviant driving behavior and accidents. These patterns have been confirmed by a metaanalysis from Clarke and Robertson (2005) that revealed small positive effects of extraversion, low consciousness, and low agreeableness on accident involvement in traffic situations.

Altogether, previous research indicates a strong relationship between anger and driving parameters such as velocity and acceleration and that anger is influenced by personal characteristics such as gender, driving experience, and driving motivation. However, there are short-comings in the literature regarding the relationships between those personal characteristics and experienced anger and driving behavior. The aim of this research was therefore to disentangle the influences of personal characteristics and experienced anger on driving performance within a simulated driving environment. Accordingly, a model was 
created within which all relevant influences on driving performance were examined and, consequently, the distinct impact of each factor was revealed. Based on the reviewed literature, the relevant influences are driving motivation, driving experience, gender, and trait and state anger (Fig. 1).

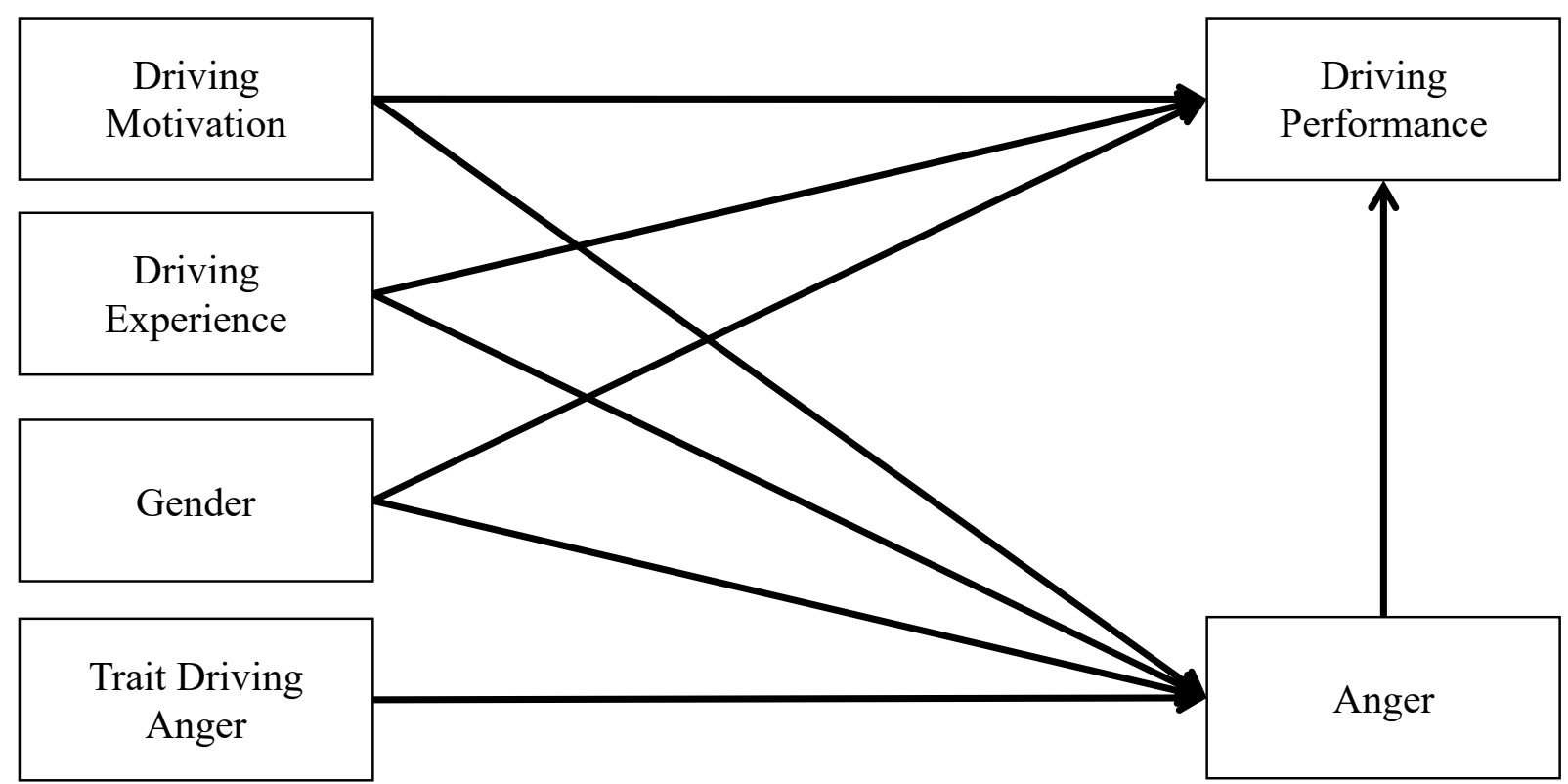

Figure 1: Proposed model of driving incorporating personal characteristics, anger and driving performance

\section{Study 1}

The lack of existing cohesive models prompted us to adopt an exploratory approach in the first study. The aim of this study was to explore the relationships between anger, personal characteristics, and driving behavior in a simulated driving environment. To induce anger in participants, emotion-inducing film clips were presented before the experiment. This method is considered to be the most effective method to elicit discrete emotions (Hewig et al., 2005; Schaefer, Nils, Sanchez \& Philippot, 2010; Westermann, Spies, Stahl \& Hesse, 1996). Participants experiencing strong anger were expected to drive faster, to accelerate more quickly, and to exhibit more speeding. The effects on driving parameters were expected to accompany the lack of driving experience, high driving motivation, and being male. To test these assumptions for the multivariate model, various traffic scenarios were designed. To account for the driving parameters, the means of longitudinal variables (speed and acceleration), lateral variables (lateral acceleration), and traffic violations (speeding) were assessed. The ethical review board approved this study. 


\subsection{Method}

\subsubsection{Participants}

In the first study, 74 drivers $(60.5 \%$ female) recruited on the university campus participated. Their ages ranged from 18 to 31 years $(M=20.70 ; S D=2.88)$, and they had had their driving license for an average of 3.12 years $(\mathrm{SD}=2.85)$. Their average yearly driving distance and total kilometers driven since they acquired their license were $4610 \mathrm{~km}$ (SD = $10,320 \mathrm{~km})$ and 20,600 km (SD =62,800 km), respectively. Participants were compensated for their participation with a small gift worth 15 Euro.

\subsubsection{Stimulus Material}

The experimental track was $5000 \mathrm{~m}$ long and consisted of three distinct, mostly rural environments with a general middle European appearance (signs, traffic rules, vegetation). The sequence of the sections was fixed. First, participants drove over a $2700 \mathrm{~m}$ country road with several curves and a driver ahead who could not be passed for $1000 \mathrm{~m}$. The participant then entered a village with a $50 \mathrm{~km} / \mathrm{h}$ speed restriction. After the village, another rural section began in which a construction site narrowed the road for approximately $300 \mathrm{~m}$. The speed limit near the construction site was $60 \mathrm{~km} / \mathrm{h}$.

\subsubsection{Design}

Participants were randomly assigned to one of two groups: 'neutral' or 'emotional.' The neutral group viewed a film clip, taken from “All the President's Men," of approximately $70 \mathrm{~s}$ duration and without emotional content (Pakula, 1976). The emotional group viewed a film clip, taken from "Schindler's List," of approximately $110 \mathrm{~s}$ that contained anger-inducing content (Spielberg, 1993). The film clips were shown before the drive on the experimental track. The clips were chosen from a database of emotion-inducing film clips based on their abilities to elicit strong discrete emotions (Schaefer et al., 2010; Westermann et al., 1996). The two film clips used in this experiment have been evaluated in terms of their abilities to fail to induce emotion (neutral group) and to induce anger (emotional group; Hewig et al., 2005; Schaefer et al., 2010).

\subsubsection{Apparatus}

The study was conducted with the driving simulator StiSim W100 from System Technology Incorporated. A Volkswagen Golf cockpit with original a steering wheel and instrument panel was used to control the car. During the simulation, the StiSim W100 registered all driving activities (i.e., velocity, acceleration, and lateral position). 


\subsubsection{Experimental Measures}

An adjusted Geneva Emotion Wheel questionnaire (GEW, Scherer, 2005; Oehl et al., 2010) was administered to participants. This questionnaire covers 16 emotions that are frequent in driving contexts. The participants were asked to rate the different emotions within each road section on a Likert scale that ranged from 1 (weak emotion) to 5 (very strong emotion). To investigate the influence of personal characteristics, trait driving anger was measured with a German version of the Driving Anger Scale (DAS; Deffenbacher et al., 1994; Steffgen, Recchia \& Ludewig, 2008). This scale includes 33 items that measure six subscales: "hostile gestures," "illegal driving," "police presence," "slow driving," “discourtesy," and "traffic obstructions." To assess driving motivation, two items were presented ('I really like to drive,' and 'Driving is important to me') and were rated on a five-point Likert scale ( $1=$ not at all; $5=$ very much). Age, gender and kilometers (per year and total) completed the measurement of personal characteristics.

The driving patterns of the participants were recorded throughout the experiment, and the mean velocity $(\mathrm{km} / \mathrm{h})$, acceleration $\left(\mathrm{m} / \mathrm{s}^{2}\right)$, and lateral acceleration $\left(\mathrm{m} / \mathrm{s}^{2}\right)$ were assessed (see Stephens \& Groeger, 2009). These parameters are recognized as sensitive performance measures in traffic situations (Bouchner et al., 2006; Deery \& Fildes, 1999). Driving violations were represented by the occurrence of speeding in the rural $(100 \mathrm{~km} / \mathrm{h}$ and $60 \mathrm{~km} / \mathrm{h}$ restricted) and village (50 km/h restricted) sections. The amount of the track covered at illegally high speeds was expressed as the percentage of the entire track.

\subsubsection{Procedure}

Initially, all participants completed a questionnaire that provided personal characteristics and driving histories. Three training scenarios preceded the actual driving task so that the participants could become comfortable with the steering behavior and graphical environment of the simulator. Within this familiarization run, the subjects drove in a large parking lot (without traffic), on a rural highway (moderate speed, low traffic density) and on an urban street (low/ moderate speed, high traffic density). Immediately after training, the groupspecific videos were shown to the anger and neutral groups. After the experimental drive, the questionnaire on driving related anger (DAS) was distributed; during the experiment, participants rated their discrete emotions on the GEW after each section (rural, village, highway). 


\subsection{Results}

\subsubsection{Drivers' reported emotions and personal characteristics}

After inducing neutral or angry emotions in the participants, a manipulation test was performed using the GEW. The anger group reported significantly increased anger immediately after the movie $(M=3.69 ; \mathrm{SD}=3.16)$ compared the neutral group $(\mathrm{M}=0.74$; $\mathrm{SD}=1.77 ; \mathrm{F}(1 ; 72)=24.72 ; \mathrm{p}<.001)$. However, this difference disappeared later in the experiment; in the emotional group, anger decreased to $0.94(\mathrm{SD}=1.92)$ on the rural road, $0.89(\mathrm{SD}=1.91)$ in the village and $1.20(\mathrm{SD}=1.93)$ on the highway. The anger levels of the neutral control group remained relatively constant or elevated from $0.82(\mathrm{SD}=1.84)$ to 1.47 $(\mathrm{SD}=2.32)$ to $1.00(\mathrm{SD}=1.74)$ across the three driving environments, respectively (no $\mathrm{F}$ values from the group comparison were significant and ranged between 0.242 and 0.938 ). The ratings of driving motivation were 3.69 ( $\mathrm{SD}=0.85)$, and the means for the DAS scores were $\mathrm{M}=3.20(\mathrm{SD}=0.47)$.

\subsubsection{Determinants of the drivers' emotions: personal factors}

The personal characteristics of gender, driving experience, driving motivation, and trait driving anger were correlated with anger (Table 1). Neither the demographic variables nor trait driving anger significantly influenced anger levels. Driving motivation was positively correlated with higher annual mileage $(\mathrm{r}=.271, \mathrm{p}<.019)$.

Table 1: Correlations of personal characteristics and anger levels in the first study

\begin{tabular}{llrrrrr} 
& & 1 & 2 & 3 & 4 & 5 \\
\hline 1 & Anger & - & & & & \\
2 & Gender & -.071 & - & & & \\
3 & Mileage & .015 & -.054 & - & & \\
& Driving & -.059 & .177 & $.271^{*}$ & - & \\
4 & Motivation & & & & & \\
5 & DAS & .006 & -.2 & -.072 & .018 & - \\
\hline
\end{tabular}

$* \mathrm{p}<.05 ; * * \mathrm{p}<01$ 


\subsubsection{Emotions, personal characteristics and driving behaviour}

In the first part of the analysis, the reported emotions and personal characteristics were associated with the driving parameters using multiple linear regressions. Gender, driving experience, driving motivation and DAS scores were used as independent variables. For anger, only the measurement points within the experiment, and not those recorded immediately after watching the films, were used. The use of these reports of anger ensured a close temporal relationship with the measured driving parameters. The four different models represented the dependent variables and focused on the longitudinal velocity, longitudinal acceleration, lateral acceleration, and speeding that were assessed during the $5000 \mathrm{~m}$ drive (Table 2). We assumed that higher levels of anger, driving motivation, being male, and being less experienced on the road would lead to declines in good driving performance. These declines were defined by higher velocities, increased (lateral and longitudinal) acceleration, and more speeding.

Mean driving speeds were affected by experienced anger, driving motivation, and gender. High anger scores $(\beta=.27 ; \mathrm{t}(68 ; 5)=2.47 ; \mathrm{p}<.016)$, driving motivation $(\beta=.25$; $\mathrm{t}(68 ; 5)=2.30 ; \mathrm{p}<.025)$ and being male $(\beta=.27 ; \mathrm{t}(68 ; 5)=2.43 ; \mathrm{p}<.018)$ added a significant amount of speed to the population mean. Acceleration was closely related to velocity $(r=.75$; $\mathrm{p}<.001)$, but the predictive model was different. High anger scores $(\beta=.32 ; \mathrm{t}(68 ; 5)=2.98$; $\mathrm{p}<.004)$ and being male $(\beta=.38 ; \mathrm{t}(68 ; 5)=3.47 ; \mathrm{p}<.001)$, but not driving motivation, increased the acceleration significantly.

Velocity was highly correlated with speeding violations throughout the track (mean correlation $\mathrm{r}=.84 ; \mathrm{p}<.001)$. This close relationship is only partly reflected by the predictive model for speeding. Driving motivation $(\beta=.26 ; \mathrm{t}(68 ; 5)=2.34 ; \mathrm{p}<.002)$ and gender (males violated the speeding restriction more often $)(\beta=.31 ; \mathrm{t}(68 ; 5)=2.83 ; \mathrm{p}<.001)$, but not anger, were significant predictors of these speeding violations.

In the domain of lateral acceleration, only driving motivation remained as a predictor; mean lateral acceleration rose with increased motivation $(\beta=.25 ; \mathrm{t}(68 ; 5)=2.14 ; \mathrm{p}<.036)$. No influences of other personal characteristics were observed. In summary, anger, driving motivation and gender were strong predictors of longitudinal and lateral variables (Table 2). 
Table 2: Multiple linear regressions of anger and personal characteristics on driving parameters in the first study

$\begin{array}{llllll}\text { Corr R2 } & \text { F } & \text { df } & \text { B } & \beta & \text { Sig. }\end{array}$

DV Velocity $(\mathrm{km} / \mathrm{h})$

$.233 \quad 4.132 \quad 5,68$

.006

Baseline

71.63

Anger

$\begin{array}{lll}1.26 & .27 & .016\end{array}$

Driving Motivation

$\begin{array}{lll}1.92 & .25 & .025\end{array}$

Driving Experience

$0 \quad .07 \quad .51$

Gender

$\begin{array}{lll}3.50 & .27 & .018\end{array}$

DAS

$0.89 \quad .06 \quad .558$

DV Acceleration $\left(\mathrm{m} / \mathrm{s}^{2}\right)$

$.241 \quad 4.316 \quad 5,68$

.002

Baseline

0.38

Anger

$\begin{array}{lll}0.04 & .32 & .004\end{array}$

Driving Motivation

$\begin{array}{lll}0.01 & .05 & .643\end{array}$

Driving Experience

$\begin{array}{lll}0 & -.02 & .873\end{array}$

Gender

$\begin{array}{lll}0.12 & .38 & .001\end{array}$

DAS

$\begin{array}{lll}0.02 & .07 \quad .525\end{array}$

DV Lateral Acceleration $\left(\mathrm{m} / \mathrm{s}^{2}\right)$

$\begin{array}{lll}.12 & 1.87 \quad 5,68\end{array}$

.152

Baseline

0.12

Anger

$\begin{array}{lll}0.01 & .19 & .099\end{array}$

Driving Motivation

$\begin{array}{lll}0.02 & .25 & .036\end{array}$

Driving Experience

$\begin{array}{lll}0 & .04 & .724\end{array}$

Gender

$\begin{array}{lll}0.01 & .07 & .536\end{array}$

DAS

$\begin{array}{lll}0.01 & .04 & .753\end{array}$

Speeding

$.224 \quad 3.93 \quad 5,68$

.007

Baseline

24.96 
Driving Motivation

Driving Experience

Gender

DAS $\begin{array}{lll}5.25 & .26 & .022\end{array}$

$\begin{array}{lll}0 & .10 & .355\end{array}$

$\begin{array}{lll}10.92 & .31 & .006\end{array}$

$\begin{array}{lll}0.72 \quad .02 & .861\end{array}$

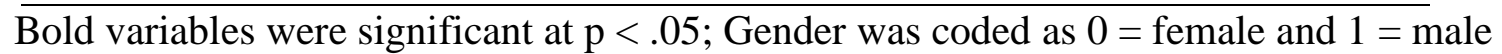

To further account for the influence of single personal characteristics on anger and driving performance, we used a structural equation model approach using the AMOS 19 statistical tool (Fig. 2).

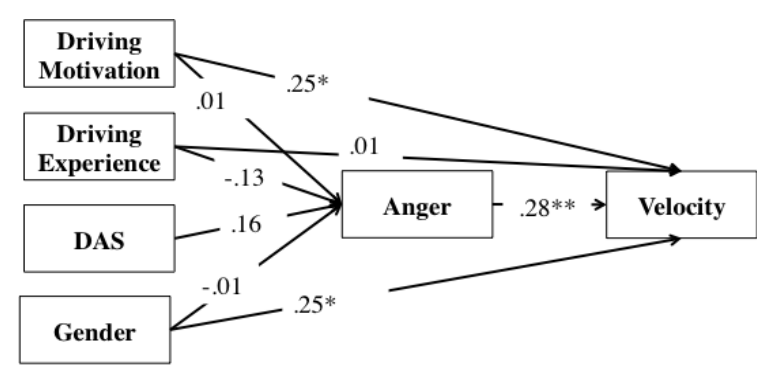

Model-Fit

$\chi^{2}=1.11 ; \mathrm{df}=3 ; \mathrm{p}<.774, \mathrm{RMSEA}=0.000, \mathrm{CFI}=1.000$

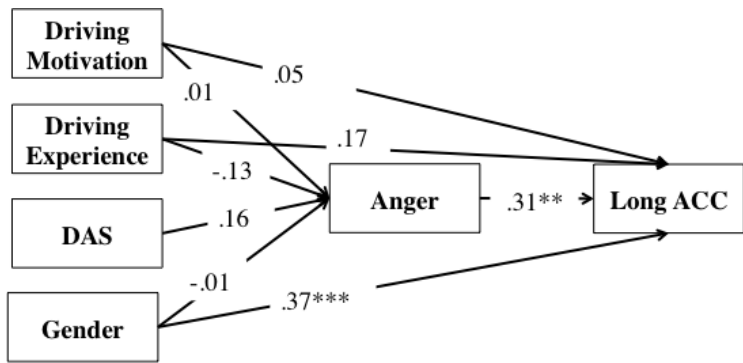

Model-Fit

$\chi 2=1.17 ; \mathrm{df}=3 ; \mathrm{p}<.758, \mathrm{RMSEA}=0.000, \mathrm{CFI}=1.000$

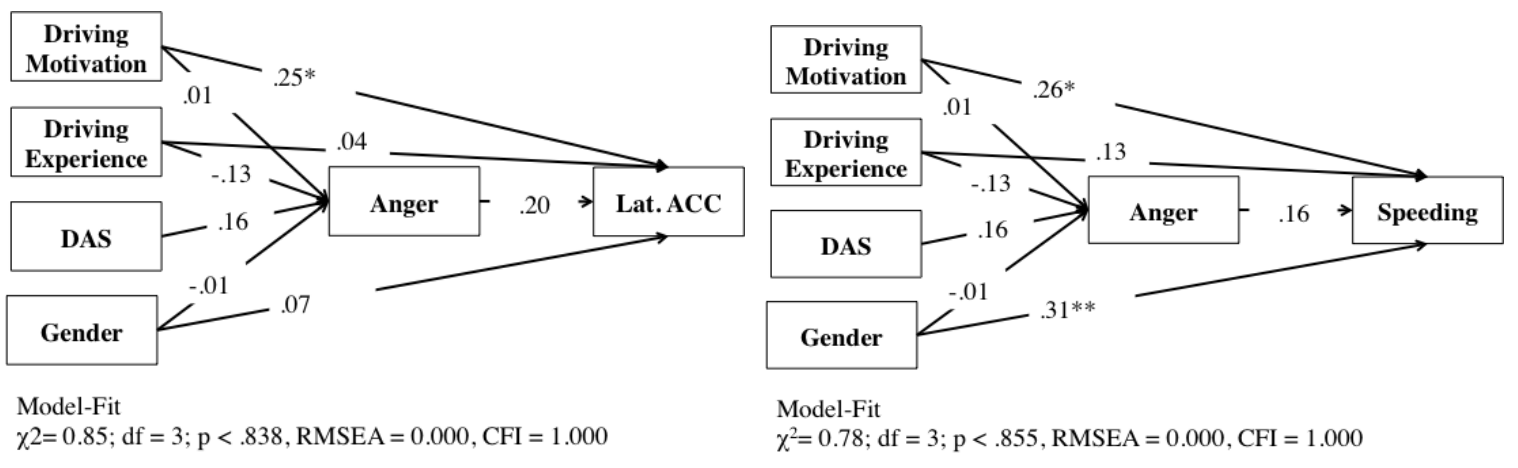

Figure 2: Path models for personal characteristics, reported anger and driving parameters (velocity, longitudinal acceleration, lateral acceleration and speeding) in the first study. $\mathrm{p}<.05 ; * * \mathrm{p}<.01 ; * * * \mathrm{p}<.001$

The quality indices for all models were the comparative fit index (CFI; values above .90 are acceptable), the root mean square error of approximation (RMSEA, values below .005 indicate close fits between data and the model) and the $\chi^{2}$ value (non-significant values indicate good fits between the sample covariance and the fitted covariance; Bentler, 1990; 
Arbuckle \& Wothke, 1999). Before the analysis began, Pearson product-moment correlations and multicolinearity statistics among independent variables were calculated. The values of the conditioning indices were below .20, which indicates a lack of multicolinearity.

The indices for the quality of the model fit were in the expected ranges; $\chi 2$ values were between 0.78 and 1.14 and the CFI and RMSEA values of all four models were optimum (1 for CFI and 0 for RMSEA). The path models revealed a pattern of influences of personal characteristics and anger on driving parameters that was similar to that of the multiple regressions. Regarding driving motivation and gender, both factors were positively associated with higher speeds $(\beta=.25)$, more speeding violations $(\beta=.26$ and .31$)$, longitudinal acceleration (only gender with $\beta=.37$ ), and lateral acceleration (only driving motivation: $\beta=.25$ ). Anger itself was not explained by personal characteristics, but anger had a significant influence on velocity $(\beta=.28)$ and speeding $(\beta=.31)$.

\subsection{Discussion of the first study}

The aim of the first study was to explore the relationships between anger, personal characteristics, and driving behavior in a simulator environment. Increased anger was hypothesized to lead to higher speeds and decreased lateral control. Specific demographics, such as high driving motivation, a lack of driving experience and being male, were predicted to influence those driving parameters in a maladaptive manner. The specific emotion of anger was induced using short film-clips, and this manipulation was initially successful; compared to the neutral group, those who viewed the anger-inducing film-clips reported approximately a 6-fold increase in anger levels. However, this effect vanished quickly. After the first potentially frustrating event on the rural road (a slow car in front of the participant), anger levels decreased to 0.70, which indicates very low levels of subjective anger. At this point, there was no difference between the neutral and the film-stimulated group. One possible explanation for this effect could be the change of contexts from watching a film clip to driving in the simulator. This change in context implies a change in emotion and might have erased the negative emotion induced by the film clip. Another possible explanation for the low levels of observed negative emotion might be that driving in a simulator can be an entertaining and exciting event. Given this possibility, both groups were taken together, and the raw anger reports were analyzed regardless of their experimental origin.

The results clearly indicate repeated correlations between the anger experienced during the drive, personal factors, and changes in driving pattern. These findings support the idea of a coherent model that involves several factors and that could affect driving behavior in various 
situations. Concordant with the literature, angry drivers drove faster and accelerated more quickly (Deffenbacher et al., 2003; Deffenbacher, Lynch, Deffenbacher et al., 2001, Stephens \& Groeger, 2009). Furthermore, highly motivated drivers and males seemed to behave in the same manner, regardless of the emotion experienced. It is well established that male drivers are prone to overestimate their driving skills (DeJoy, 1992; Ulleberg, 2002; Yagil, 1998) and misinterpret the probability of doing harm in potentially dangerous traffic situations, which could lead to higher speeds (Hennessy \& Wiesenthal, 1999). The impact of driving motivation on driving performance may have been mediated by anger, as this effect has previously been shown by Philippe et al. (2009). However, this outcome was not the case in our first study for the following reasons:

(a) no direct relationship was found between driving motivation and anger, and (b) even after controlling for the emotion, highly motivated drivers drove at higher speeds and exhibited stronger lateral acceleration. These findings indicate that being highly motivated to drive a car can lead to stronger longitudinal and lateral driving patterns per se because these drivers may inherently enjoy this type of driving or pursue other goals such as achieving a flow state when entering certain speeds.

Interestingly, none of the demographic characteristics interacted with the reported anger levels. This finding is contrary to the literature, which suggests that the driving anger scale (Deffenbacher et al., 1994; Deffenbacher et al., 2003), driving motivation (Philippe et al., 2009), gender, age, and mileage are related to at least some aspects of driving-related anger (Björklund, 2008, Lajunen \& Parker, 2001). Our study did not find these relationships, which may be due to differences in the method of inciting the anger. In this study, we used film material that was unrelated to traffic situations. When entering the simulator, anger levels were no longer related to the film clips because of the new context. Driving motivation and trait driving anger predicted context-specific anger that was due to the traffic situations but failed to explain other sources of anger. This finding raises the question of whether the changes in the emotional environment during the experiment (from the film to the driving task) and our assessment of the anger in the driving simulator were appropriate for our experiments.

Thus, a second study was performed with the primary goal of reproducing the results of the first explorative study. Furthermore, the focus of the emotional manipulation was shifted from an external film clip to the traffic situation itself, which should help to ensure the relationship between anger and driving behavior patterns. The driving segments were standardized to 
make the track segments more homogenous, to reduce variations in driving patterns, and to enhance measurement precision. This study was also approved by the ethical review board.

\section{Study 2}

\subsection{Method}

\subsubsection{Participants}

Eighty drivers (60\% female) participated in this study. The participants' ages ranged from 18 to 52 years $(\mathrm{M}=24.47 ; \mathrm{SD}=5.99)$, and the average driving experience was 6.49 years $(\mathrm{SD}=5.66)$. Participants drove, on average, $7870 \mathrm{~km}$ per year $(\mathrm{SD}=9240)$, and had a total mileage of $73,980 \mathrm{~km}(\mathrm{SD}=112,600)$. Participants were mostly recruited on the university campus. To prevent overlap with the sample of the first study, the participants were asked whether they participated in a driving simulator experiment at this institute within the last four weeks. Participants were compensated for their participation with a small gift worth 15 Euro.

\subsubsection{Stimulus Material}

The simulated track was a $17,120 \mathrm{~m}$ rural route over which four critical events took place. The first situation was a construction site blocking the progress of the participant for two minutes, thereby preventing smooth driving. There was no possibility to pass the construction site in less than two minutes due to steady oncoming traffic. The second situation was a car driving very slowly in front of the participant. Again, passing the car was not possible until the road broadened, which forced the participant to stay behind the car for approximately two minutes. The third situation consisted of a car in front of the participant that braked suddenly and forced the participant to react quickly. The fourth situation was a barely secured hole in the street on a curve that the participant had to dodge to avoid crashing. After each scenario, a standardized section of road $2200 \mathrm{~m}$ in length with various curves served as the baseline for driving behavior analysis. Over the course of the experiment, the scenarios were presented in four different orders to control for sequence effects.

\subsubsection{Experimental Measures}

The driver was questioned about his/her emotion after the drive to avoid interrupting the participant and to prevent potential behavioral cues. Four pictures of the critical sections of the experimental drive were provided to help remind participants of the specific situations. As in study one, each situation was rated with a revised edition of the GEW (Oehl et al., 2010; Scherer, 2005) that covers 16 emotions relevant for driving contexts. The participants were allowed to rate up to three different emotions within each critical situation on a Likert scale 
ranging from 1 (weak emotion) to 5 (very strong emotion). The emotions were later analyzed and compared with the specific driving behaviors displayed during the four critical situations. The same personal characteristics assessed in study 1 were assessed in study 2 (gender, mileage [as kilometers per year], driving motivation and DAS scores).

Driving behavior over the $2200 \mathrm{~m}$ was recorded after each of the four critical situations and, as in the first study, the mean velocities $(\mathrm{km} / \mathrm{h})$ and longitudinal and lateral accelerations $(\mathrm{m} / \mathrm{s} 2)$ were assessed. Speeding was measured as the percentage of two sections of the track over which the participants exceeded the speed limit (a $700 \mathrm{~m}$ zone with a speed limit of 70 $\mathrm{km} / \mathrm{h}$ and a $900 \mathrm{~m}$ zone with a speed limit of $100 \mathrm{~km} / \mathrm{h}$ after each event).

\subsubsection{Apparatus \& Procedure}

As in the first study, the StiSim 100 was used in this experiment. Three training scenarios preceded the experimental drive. Directly after the experiment, the DAS was completed, and the emotions experienced were assessed using photos of the critical situations to help the participants remember the specific situations (Gray \& Watson, 2007).

\subsection{Results}

Similar to study one, the data were analyzed using correlations (between anger and personal characteristics), multiple linear regressions, and path analyses using the SEMs.

\subsubsection{Occurrence of drivers' reported emotions and personal characteristics}

Anger was reported an average of 2.23 times $(\mathrm{SD}=1.08$, out of a maximum of four) during the experiment. The mean intensity of anger experienced was $1.65(\mathrm{SD}=1.01)$, which indicates low anger intensity (given that the range of the GEW was 1 to 5), but was slightly higher than the anger levels observed in study one $(\mathrm{M}=1.09)$. The mean for the DAS was $3.19(\mathrm{SD}=0.50)$, and the mean rating of driving motivation in the tested population was $3.97(\mathrm{SD}=0.91)$.

\subsubsection{Determinants of the drivers' emotions: personal factors}

As in study one, personal characteristics and anger were correlated (Table 3). Trait driving anger, as measured with the DAS, correlated positively with anger $(r=.272 ; p<.015)$. Additionally, more intense anger was observed among highly motivated drivers $(r=.314$, $\mathrm{p}<.005)$. 
Table 3: Correlations of personal characteristics and anger levels in the second study

\begin{tabular}{lllllll} 
& & 1 & 2 & 3 & 4 & 5 \\
\hline 1 & Anger & - & & & & \\
2 & Gender & -.119 & - & & & \\
3 & Mileage & .074 & .14 & - & & \\
4 & Driving & & & & & \\
& Motivation & $.314 * *$ & -.214 & $.349 * * *$ & - & \\
5 & DAS & $.272 *$ & -.196 & .036 & .160 & - \\
$* \mathrm{p}<.05 ; * * \mathrm{p}<.01 ; * * * \mathrm{p}<.001$ & & & &
\end{tabular}

\subsubsection{Emotions, personal characteristics and driving behaviour}

The relationship between self-reported anger and the participants' driving parameters were analyzed with multiple linear regression and SEM models. Driving motivation, driving experience, gender, DAS scores and anger were used as independent variables. The dependent variables were the same driving performance parameters used in study 1 (longitudinal and lateral velocity, acceleration and speeding) and were recorded for $2200 \mathrm{~m}$ after each of the four critical events.

Table 4: Multiple linear regressions of anger and personal characteristics on driving parameters in the second study

$$
\begin{array}{llllll}
\text { Corr R2 } & \text { F } & \text { df } & \text { B } & \beta & \text { Sig. }
\end{array}
$$

DV Velocity $(\mathrm{km} / \mathrm{h})$

$6.97 \quad 5,74$

.001

Baseline

81.79

Anger

$\begin{array}{lll}2.39 & .30 & .006\end{array}$

Driving Motivation

$\begin{array}{lll}3.18 & .35 & .003\end{array}$

Driving Experience

$\begin{array}{lll}0 & -.02 & .875\end{array}$

Gender

$\begin{array}{llll}6.32 & .37 & .001\end{array}$

DAS

$\begin{array}{lll}-1.05 & -.06 & .538\end{array}$

DV Acceleration $\left(\mathrm{m} / \mathrm{s}^{2}\right)$

$\begin{array}{lll}.155 & 2.71 \quad 5,74\end{array}$

.026 
Baseline

0.37

Anger

$\begin{array}{lll}0.03 & .31 & .010\end{array}$

Driving Motivation

$\begin{array}{lll}0.01 & .13 & .293\end{array}$

Driving Experience

$\begin{array}{lll}0 & -.17 & .163\end{array}$

Gender

$\begin{array}{lll}0.04 \quad .22 & .065\end{array}$

DAS

$\begin{array}{lll}-0.03 & -.14 & .216\end{array}$

DV Lateral Acceleration (m/ $\left./ \mathrm{s}^{2}\right)$

.007

Baseline

1.14

Anger

$\begin{array}{llll} & 0.11 & .33 & .003\end{array}$

Driving Motivation

$0.07 \quad .18$

.137

Driving Experience

$\begin{array}{lll}0 & -.11 & .309\end{array}$

Gender

$\begin{array}{lll}0.27 & .38 & .001\end{array}$

DAS

$\begin{array}{lll}-0.09 & -.13 & .235\end{array}$

Speeding

.001

Baseline

42.11

Anger

Driving Motivation

Driving Experience

Gender

DAS $\begin{array}{llll}5.56 & .31 & .003\end{array}$

$\begin{array}{llll}6.76 & .33 & .003\end{array}$

$\begin{array}{llll}0 & -.01 & .947\end{array}$

$\begin{array}{llll}16.54 & .44 & .000\end{array}$

$\begin{array}{lll}-2.69 & -.07 & .468\end{array}$

Bold variables were significant at $\mathrm{p}<.05$; Gender was coded as $0=$ female and $1=$ male

As in study one, mean driving speeds were positively affected by reported anger $(\beta=.30$ $\mathrm{t}(74 ; 5)=2.85 ; \mathrm{p}<.006)$, driving motivation $(\beta=.35 \mathrm{t}(74 ; 5)=3.11 ; \mathrm{p}<.003)$ and gender (males drove faster; $\beta=.37 \mathrm{t}(74 ; 5)=3.62 ; \mathrm{p}<.001$ ). Longitudinal acceleration was only influenced by anger levels, and people who drove angrily accelerated more quickly $(\beta=.31$ $\mathrm{t}(74 ; 5)=2.63 ; \mathrm{p}<.010)$. No other tested relationships were significant. The lateral 
acceleration model identified anger $(\beta=.33 \mathrm{t}(74 ; 5)=3.04 ; \mathrm{p}<.003)$ and gender (again, males; $\beta=.38 \mathrm{t}(74 ; 5)=3.49 ; \mathrm{p}<.001)$ as positively influencing lateral acceleration.

The longitudinal driving parameters yielded strong correlations with speeding (mean correlation $\mathrm{r}=.48 ; \mathrm{p}<.001)$. This finding was mirrored by the set of factors influencing this violation that included anger $(\beta=.31 \mathrm{t}(74 ; 5)=3.05 ; \mathrm{p}<.003)$, driving motivation $(\beta=.33$ $\mathrm{t}(74 ; 5)=3.04 ; \mathrm{p}<.003)$, and being male $(\beta=.44 \mathrm{t}(74 ; 5)=4.34 ; \mathrm{p}<.001)$ (Table 4).

These results of study two were very similar to those from the first study and strongly indicate that highly motivated, angry males were prone to drive faster, accelerate more quickly and showed a tendency toward higher lateral acceleration. Path analyses revealed model fits that were similar to those of study one and were, overall, very strong: the ranges of the $\chi 2$, CFI and RMSEA values for all four models were between 2.31 and 4.80, 0.961 and 1.0 and 0.0 and 0.087 , respectively. Analogous to the multiple regressions, the path models revealed a consistent relationship between anger levels and driving parameters (coefficients ranged from $\beta=.27-.29)$. Anger itself was influenced by trait anger tendencies $(\beta=.22-.23)$ and driving motivation $(\beta=.24-.29)$ but not gender $(\beta=0.0-.01)$ or driving experience $(\beta=.04)$. Nevertheless, gender had a direct positive effect on all driving parameters $(\beta=.24-.44)$; i.e., males drove faster (and over the legal limit) and accelerated (longitudinally and laterally) more quickly. The same pattern was observed for driving motivation $(\beta=.23-.37)$ (Fig. 3).
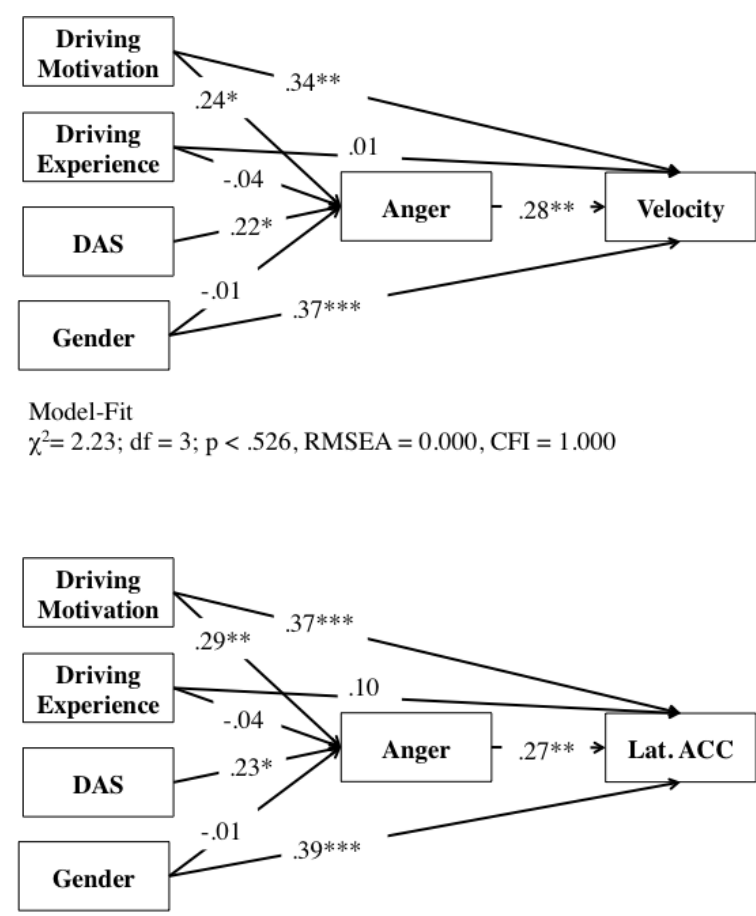

Model-Fit

$\chi 2=4.80 ; \mathrm{df}=3 ; \mathrm{p}<.187, \mathrm{RMSEA}=0.087, \mathrm{CFI}=0.961$
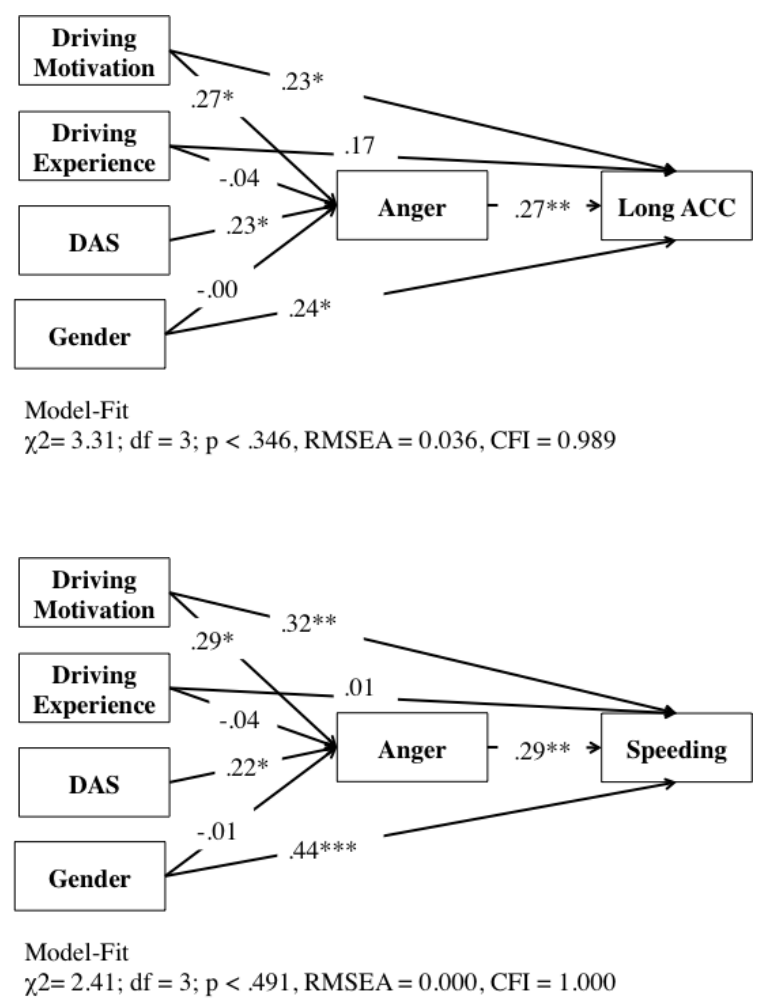
Figure 3: Path Models of the personal characteristics, reported anger and driving parameters from the second study. $\mathrm{p}<.05 ; * * \mathrm{p}<.01 ; * * * \mathrm{p}<.001$

\subsection{Discussion of the second study}

The aim of the second study was to validate the findings of the first study and to test another method of inducing anger in a simulated driving environment. The basic results of study one were successfully replicated: high levels of anger, driving motivation and being male led to higher speeds, greater longitudinal and lateral acceleration and more speeding violations.

The elicitation of anger in the driving situation in study two was more efficient than that of study one in which film clips were used to induce emotions. The reported anger increased from approximately 1.09 in study one to 1.65 in study two. This increase may have been responsible for the occurrence of more frequent and stronger effects; significant effects of anger levels on lateral acceleration and speeding behavior were only observed in the second study. This differential influence of angry across studies may indicate the presence of an anger threshold and suggest that traffic participants have to experience a certain level of anger well before they will exhibit risky driving behaviors. If anger level is the defining factor, the qualities of the anger could be neglected for these types of analyses, and different types of anger could lead to similar driving outcomes. This idea has been put forth previously in the meta-analysis of anger and aggressive driving by Nesbit, Conger and Conger (2007).

Analyses of the correlations between personal characteristics and anger revealed that driving motivation and DAS scores were related to increased anger. This relationship has been found previously by researchers such as Philippe et al. (2009), who showed that obsessively passionate drivers are prone to experience greater anger and, consequently, exhibit more aggressive driving behaviors. Analyses of DAS scores showed that they were not influenced by any other personal characteristic. Furthermore, MANOVA analysis for moderator effects revealed that DAS scores did not directly predict maladaptive driving. Therefore, DAS scores appear to have inferior predictive validity compared to measures of state emotion (i.e., the GEW) in traffic situations. 


\section{General Discussion and Conclusion}

The aim of this paper was to reveal the influence of emotions on driving in relation to other personal characteristics of the driver. Two studies employing different methods of eliciting emotion and various traffic events and driving environments were conducted. Both studies showed that anger and personal characteristics were two distinct factors that influenced longitudinal and lateral driving parameters in specific ways. The first study induced emotion using short film clips. This method of inducing emotion was successful at the beginning of the experiment, but the effect decreased quickly, and both groups completed the experiment at similar emotional levels. However, the participants who felt any degree of anger due to the situational characteristics drove faster and accelerated more quickly (longitudinally and laterally).

Those results were largely replicated in the second study in which the method of inducing emotion was altered. In study two, traffic events (a slow car, a construction site, a braking car and a dangerous hole in the street) were used to elicit anger. The emotional intensities were slightly higher in study two than in study one (study one: $\mathrm{M}=1.09$ vs. study two: $\mathrm{M}=1.65$ ). Furthermore, in the second study, driving motivation positively influenced anger. Participants who showed high motivation to drive may have been more angered by the goal-blocking nature of the traffic environment. This finding prompted the assumption that the anger elicited in study one might not have been directly related to the traffic environment. This idea is supported by the finding that there was no relationship between the DAS scores and driving anger in study one, while this relationship was significant in the second study. Therefore, the quality of the anger induced in study one could be described as largely independent of the traffic environment, whereas in study two, the anger was more directly related to the driving task. However, in both studies, anger negatively influenced various driving parameters including velocity, acceleration and lateral control. These findings prompted the assumption that anger, regardless of how it is elicited, is a suitable predictor of declines in specific performance parameters. This assumption supports the findings of a meta-analysis by Nesbit, Conger and Conger (2007), who found similar effect sizes between various types of anger and driving behavior.

The main effects of driving motivation and gender were strong in both studies, and participants who scored high on driving motivation showed the same maladaptive behavior as angered participants. Even after controlling for experienced anger, these participants drove 
faster and exhibited quicker lateral acceleration. These findings extend the frustrationaggression hypothesis of Dollard, Doob, Miller, Mowrer and Sears (1939) and the idea of a chain reaction that begins with (potentially frustrating) traffic events, proceeds to the importance of driving, then to the elicitation of anger and then culminates in aggressive driving patterns (Philippe et al., 2009; Stephens \& Groeger, 2009). Our research indicates another direct route to maladaptive driving and that no frustration or anger is needed to elicit higher speeds. Drivers who value driving as an important activity seem to enjoy driving at higher speeds and taking the risks that accompany this behavior.

This phenomenon was especially true for the male participants in both studies. The discussion of study one noted that males are prone to underestimate the dangers of a possible harmful situation (Hennessy \& Wiesenthal, 1999; Laapotti \& Keskinen, 2004) and are constantly overestimating their driving skills (DeJoy, 1992; Ulleberg, 2002; Yagil, 1998); these effects seemed to present in both studies. Independent of anger and driving motivation, males drove faster, accelerated more quickly, sped more, and exhibited more intense lateral acceleration (the last effect was only present in study two). Males did not exhibit elevated driving motivation relative to females, which indicates the importance of other motivations, and shifts the focus to the subjective skill levels and risk perception processes of males (Deery \& Fildes, 1999).

Trait driving anger, as measured with the DAS, did not affect observed driving behavior, which is concordant with the findings of Stephens and Groeger (2009), who showed that situational aspects and online-appraisals in situations that include frustrating or angering events are highly more effective in predicting driving behavior. Therefore, in the simulated environments of both studies, the DAS score lost some predictive validity (see Deffenbacher et al., 2003 for contrasting results), and more proximal measures of state anger, such as the GEW, gained validity. Thus, future research should employ context-specific, sensitive measures of anger such as the GEW to validate state anger and its influence independently of trait anger and personal characteristics.

Another interesting outcome of this research is that driving experience did not significantly affect driving performance. This finding is somewhat counterintuitive because novice drivers should be prone to maladaptive driving behaviors such as poor lateral control (Krahé \& Fenske, 2002). However, this relationship was not observed in either of our simulator studies. 
It is possible that our assessments in the simulator were not sensitive to the low levels of driving experience in our samples. Moreover, analyses of attention processes and braking reaction times rather than driving speeds and accelerations may have revealed differences due to driving experience. Attention processes and braking reaction times require more sophisticated mental models and benefit vastly from a greater exposure to traffic (Ferguson, 2003; McKnight \& McKnight, 2000).

The limitations of this study are fourfold. First, the drive was simulated in the laboratory, and the situations were artificial. In contrast, real traffic is more complicated and is accompanied by greater situational variation, which leads to different emotional levels and influences on driving patterns. The traffic situations in study two were designed to overcome this problem by presenting four completely distinct situations to evoke anger. The results suggest that this general pattern of effects can be predicted in all contexts. Nevertheless, only rural/village roads were used, which is important to consider when aggregating and generalizing the results. Congested highways or rush-hour city settings may produce different patterns and new effects, which could easily disappear when averaged with other contexts.

The second limitation is that this study provides no explanation for why an emotion, high driving motivation, or being male changes driving behavior. Every construct has possible mediating features, such as poor risk assessment when angry (Lerner \& Keltner, 2001; Mesken et al., 2007) or an overestimation of subjective skill levels among male participants (DeJoy, 1992; Ulleberg, 2002; Yagil, 1998). The anger-risk relationship was derived only from driving patterns to minimize interaction with the participants and to prevent conscious awareness of this construct among participants. In contrast to Mesken et al. (2007), Stephens and Groeger (2009) did not find any relationship between anger and threat evaluations in a simulator study, which makes it plausible that emotions and risk assessment are highly dependent on the current situation. The hypothesis that the overestimation of one's own skills and faulty risk assessments in any given situation are characteristic of male participants might be supported by the finding that, even after controlled for anger, driving motivation and driving experience, men's driving performance was still worse than that of women. The addition of subjective skill levels, as measured by the driver skill inventory (Lajunen \& Sumala, 1995), to this type of research would be useful in further elucidating this issue. 
The third limitation of this study is that the reported emotions in both experiments were quite weak; this phenomenon seems to be a problem with many studies performed in a driving simulator and in real traffic experiments. The average strength of anger obtained by Mesken, Hagenzieker, Rothengatter and De Waard (2007) was 1.4, which is higher than the intensities reported in study one but lower than those of study two. Generally, weak levels of evoked anger could prevent the elucidation of important associations between emotion and behavior. From a quality perspective, a comparison between the first study, with its unspecific anger levels, and the second study, with context specific anger, revealed a more consistent pattern of relationships between anger and driving performance in study two. However, an intensity threshold may lie well above the levels of anger assessed, and perhaps exceeding this threshold could lead to more and stronger changes in driving behavior. To test this assumption, a setting with increased task demands (e.g., driving in a city during rush-hour) should be employed (Hennessy \& Wiesenthal, 1999). In a study from Roidl, Frehse, Oehl and Höger (2013), text-based scenarios triggered increases in reported anger when they incorporated greater traffic densities and time pressures.

Another limitation is that emotions were reported after the experiment. This assessment might have invited the participants to think about the experienced situations and compare them to similar stereotypical episodes from their mental model (e.g., waiting at a construction site, being behind a slow car). This process may have triggered artificial emotional responses. However, to avoid interrupting the driving task or providing potential behavioral cues, this procedure of post-hoc assessment seemed to be pragmatic. Furthermore, the driving behaviors observed in this experiment are comparable to those of other studies that collected data during simulated runs (Stephens \& Groeger, 2009) and, more importantly, after the simulated runs (Deffenbacher et al., 2003; Philippe et al., 2009).

In conclusion, the research presented in this paper showed that anger, high driving motivation, and being male are, independent of one another, significant predictors of risky driving behaviors such as high velocity and speeding. These predictors may impede safe driving and therefore increase the risk of accidents in traffic.

\section{Acknowledgement}

This research project was supported by a grant (F.A.-Nr. 2006.63) from the 'Arbeitsgemeinschaft Innovative Projekte' (AGIP) of the Ministry of Science and Culture, Lower Saxony, Germany. 


\section{References}

AAA Foundation for Traffic Safety (2009). Aggressive driving: Research update. Washington, DC: AAA Foundation for Traffic Safety http://www.aaafoundation.org/pdf/Aggressive DrivingResearchUpdate2009.pdf.

Aarts, L., \& Van Schagen, I. (2006). Driving speed and the risk of road crashes: A review. Accident Analysis and Prevention, 38(2), 215-224.

Arbuckle, J. L., \& Wothke, W. (1999). Amos users' guide; version 4.0. Chicago, IL: SmallWaters Corporation.

Arthur, W., Jr., \& Doverspike, D. (2001). Predicting motor vehicle crash involvement from personality measure and driving knowledge test. Journal of Prevention \& Intervention in the Community, 22, 35-42.

Arthur, W., Jr., \& Graziano, W. G. (1996). The five-factor model, conscientiousness, and driving accident involvement. Journal of Personality, 64, 593-618.

Bentler, P. (1990). Comparative fit indexes in structural models. Psychological Bulletin, 107, 238-246.

Björklund, G. M. (2008). Driver irritation and aggressive behavior. Accident Analysis and Prevention, 40(3), 1,069-1,077.

Bouchner, P., Pieknik, R., Novotny, S., Pekny, J., Hajny, M., \& Borzova, C. (2006). Fatigue of car drivers - Detection and classification based on the experiments on car simulators. WSEAS Transactions on Systems, 5(12), 2,789-2,794.

Britt, T. W., \& Garrity, M. J. (2006). Attributions and personality as predictors of the road rage response. British Journal of Social Psychology, 45, 127-147.

Brown, I. D., \& Groeger, J. A. (1988). Risk perception and decision taking during the transition between novice and experienced driver status. Ergonomics, 31(4), 585-597. 
Cai, H., \& Lin, Y. (2011). Modelling of operators' emotion and task performance in a virtual driving environment. International Journal of Human Computer Studies, 69(9), $571-587$.

Cellar, D. F., Nelson, Z. C., \& Yorke, C. M. (2000). The five-factor model and driving behavior: Personality and involvement in vehicular accidents. Psychological Reports, 86, 454-456.

Chliaoutakis, J. E., Demakakos, P., Tzamalouka, G., Bakou, V., Koumaki, M., \& Darviri, D. (2002). Aggressive behavior while driving as predictor of self-reported car crashes. Journal of Safety Research, 33, 431-443.

Clarke, S., \& Robertson, I. (2005). A meta-analytic review of the Big Five personality factors and accident involvement in occupational and non-occupational settings. Journal of Occupational and Organizational Psychology, 78(3), 355-376.

Dahlen, E. R., \& White, R. P. (2006). The Big Five factors, sensation seeking, and driving anger in the prediction of unsafe driving. Personality and Individual Differences, 41, 903-915.

De Winter, J. C. F., De Groot, S., Mulder, M., Wieringa, P. A., Dankelman, J., \& Mulder, J. A. (2009). Relationships between driving simulator performance and driving test results. Ergonomics, 52(2), 137-153.

Deery, H. A., \& Fildes, B. N. (1999). Young novice driver subtypes: Relationship to highrisk behavior, traffic accident record, and simulator driving performance. Human Factors: The Journal of the Human Factors and Ergonomics Society, 41(4), 628-643.

Deffenbacher, J. L., Deffenbacher, D.M., Lynch, R. S., \& Richards, T. L. (2003). Anger, aggression, and risky behavior: A comparison of high and low anger drivers. Behavior Research and Therapy, 41, 701-718. 
Deffenbacher, J. L., Huff, M. E., Lynch, R. S., Oetting, E. R., \& Salvatore, N. F. (2000). Characteristics and treatment of high anger drivers. Journal of Counseling Psychology, 47, $5-17$.

Deffenbacher, J. L., Lynch, R. S., Oetting, E. R., \& Yingling, D. A. (2001). Driving anger: Correlates and a test of state-trait theory. Personality and Individual Differences, 31, $1,321-1,331$.

Deffenbacher, J. L., Oetting, E. R., \& Lynch, R. S. (1994). Development of a driving anger scale. Psychological Reports, 74, 83-91.

DeJoy, D.M. (1992). An examination of gender differences in traffic accident risk perception. Accident Analysis and Prevention, 24(3), 237-246.

Destatis (2012). Unfallgeschehen im Straßenverkehr 2011. Statistisches Bundesamt: Wiesbaden.

Dollard, J., Doob, L. W., Miller, N. E., Mowrer, O. H., \& Sears, R. R. (1939). Frustration and aggression. New Haven, CN: Yale University Press.

Dula, C., \& Ballard, M. (2003). Development and evaluation of a measure of dangerous, aggressive, negative emotional, and risky driving. Journal of Applied Social Psychology, 33(2), 263-282.

Dula, C. S., \& Geller, E. S. (2003). Risky, aggressive, or emotional driving: Addressing the need for consistent communication in research. Journal of Safety Research, 34, 599-666.

Ellison-Potter, P., Bell, P., \& Deffenbacher, J. (2001). The effects of trait driving anger, anonymity, and aggressive stimuli on aggressive driving behavior. Journal of Applied Social Psychology, 31, 431-443.

Ferguson, S. A. (2003). Other high risk factors for young drivers: How graduated licensing does, doesn't, or could address them. Journal of Safety Research, 34(1), 71-77. 
Fisher, D. L., Laurie, N. E., Glaser, R., Connerney, K., Pollatsek, A., Duffy, S. A., \& Brock, J. (2002). The use of an advanced driving simulator to evaluate the effects of training and experience on drivers' behavior in risky traffic scenarios. Human Factors, 44, 287-302.

Gray, E. K., \& Watson, D. (2007). Assessing positive and negative affect via self report. In J. Coan, \& J. Allen (Eds.), Handbook of emotion elicitation and assessment (pp. 171-184) Oxford University Press.

Groeger, J. A., \& Chapman, P. R. (1996). Judgement of traffic scenes: The role of danger and difficulty. Applied Cognitive Psychology, 10(4), 349-364.

Hennessy, D. A., \& Wiesenthal, D. L. (1999). Traffic congestion, driver stress, and driver aggression. Aggressive Behavior, 25, 409-423.

Hewig, J., Hagemann, D., Seifert, J., Gollwitzer, M., Naumann, E., \& Bartussek, D. (2005). A revised film set for the induction of basic emotions. Cognition and Emotion, 19(7), 1,0951,109 .

Krahé, B., \& Fenske, I. (2002). Predicting aggressive driving behavior: The role of macho personality, age, and power of car. Aggressive Behavior, 28, 21-29.

Laapotti, S., \& Keskinen, E. (2004). Has the difference in accident patterns between male and female drivers changed between 1984 and 2000? Accident Analysis and Prevention, $36(4), 577-584$.

Laapotti, S., Keskinen, E., Hatakka, M., \& Katila, A. (2001). Novice drivers ì accidents and violations - A failure on higher or lower hierarchical levels of driving behavior. Accident Analysis and Prevention, 33, 759-769.

Lajunen, T. (2001). Personality and accident liability: Are extraversion, neuroticism and psychoticism related to traffic and occupational fatalities? Personality and Individual Differences, 31, 1,365-1,373. 
Lajunen, T., \& Parker, D. (2001). Are aggressive people aggressive drivers? A study of the relationship between self-reported general aggressiveness, driver anger and aggressive driving. Accident Analysis and Prevention, 33, 243-255.

Lajunen, T., Parker, D., \& Stradling, S. G. (1998). Dimensions of driver anger, aggressive and Highway Code violations and their mediation by safety orientation in UK drivers. Transportation Research Part F, 1, 107-121.

Lajunen, T., \& Sumala, H. (1995). Driving experience, personality and skill- and safetymotive dimensions in drivers' self-assessments. Personality and Individual Differences, 19, 307-318.

Lerner, J. S., \& Keltner, D. (2001). Anxiety, anger and risk. Journal of Personality and Social Psychology, 81, 146-159.

Martin, N. G., \& Boomsma, D. I. (1989). Willingness to drive when drunk and personality: A twin Study. Behavior Genetics, 19, 97-111.

Matthews, G., Dorn, L., Hoyes, T. W., Davies, D. R., Glendon, A. I., \& Taylor, R. G. (1998). Driver stress and performance on a driving simulator. Human Factors, 40, 136-149.

Maxwell, J. P., Grant, S., \& Lipkin, S. (2005). Further validation of the propensity for angry driving scale in British drivers. Personal and Individual Differences, 38, 213-224.

McKnight, A. J., \& McKnight, A. S. (2000). The behavioral contributors to highway crashes of youthful drivers. Proceedings of the 44th annual conference of the Association for the Advancement of Automotive Medicine (pp. 321-346). Des Plaines: IL: Association for the Advancement of Automotive Medicine.

Mesken, J., Hagenzieker, M. P., Rothengatter, T., \& De Waard, D. (2007). Frequency, determinants, and consequences of different drivers' emotions: An on-the-road study using self-reports, (observed) behavior, and physiology. Transportation Research Part F, 10(6), $458-475$. 
Mesken, J., Lajunen, T., \& Sumala, H. (2002). Interpersonal violations, speeding violations and their relation to accident involvement in Finland. Ergonomics, 45, 469-483.

Nesbit, S. M., Conger, J. C., \& Conger, A. J. (2007). A quantitative review of the relationship between anger and aggressive driving. Aggression and Violent Behavior, 12, $156-176$.

NHTSA (2008). National Motor Vehicle Crash Causation Survey. U.S. Department of Transportation, National Highway Traffic Safety AdministrationD.C.: Washington.

Oehl, M., Roidl, E., Frehse, B., Suhr, J., Siebert, F. W., Pfister, H. -R., \& Höger, R. (2010). Das Driving Emotion Wheel: Welche Emotionen hat der Autofahrer? In C. Frings, A. Mecklinger, D. Wentura, \& H. Zimmer (Eds.), Beiträge zur 52. Tagung experimentell arbeitender Psychologen - TeaP 2010 (S. 279). Lengerich, Deutschland: Pabst Science Publishers.

Pakula, A. J. (Director). (1976). All the President's Men (Movie). Burbank: Warner Bros. Paleti, R., Eluru, N., \& Bhat, C. R. (2010). Examining the influence of aggressive behavior on driver injury severity in traffic crashes. Accident Analysis and Prevention, 42(6),1,839-1,854.

Parker, D., Lajunen, T., \& Sumala, H. (2002). Anger and aggression among drivers in three European countries. Accident Analysis and Prevention, 34, 229-235.

Pestonjee, D.M., \& Singh, U. B. (1980). Neuroticism-extraversion as correlates of accident occurrence. Accident Analysis and Prevention, 12, 201-204.

Philippe, F., Vallerand, R. J., Richer, I., Vallières, E. F., \& Bergeron, J. (2009). Passion for driving and aggressive driving behavior: A look at their relationship. Journal of Applied Social Psychology, 39, 3,020-3,043.

Reason, J., Manstead, A., Stradling, S., Baxter, J., \& Campbell, K. (1990). Errors and violations on the roads: A real distinction? Ergonomics, 31, 1,315-1,332.

Roidl, E., Frehse, B., Oehl, M., \& Höger, R. (2013). The emotional spectrum in traffic situations: Results of two online-studies. Transportation Research Part F, 18, 168-188. 
Rosenbloom, T., Shahar, A., Elharar, A., \& Danino, O. (2008). Risk perception of driving as a function of advanced training aimed at recognizing and handling risks in demanding driving situations. Accident Analysis and Prevention, 40(2), 697-703.

Schaefer, A., Nils, F., Sanchez, X., \& Philippot, P. (2010). Assessing the effectiveness of a large database of emotioneliciting films: A new tool for emotion researchers.

Cognition and Emotion, 24(7), 1,153-1,172.

Scherer, K. (2005). What are emotions? And how can they be measured? Social Science Information, 44(4), 695-729.

Shinar, D. (1998). Aggressive driving: the contribution of the drivers and the situation. Transportation Research Part F, 1, 137-160.

Shinar, D., Schechtman, E., \& Compton, R. (2001). Self-reports of safe driving behaviors in relationship to sex, age, education and income in the US adult driving population. Accident Analysis and Prevention, 33(1), 111-116.

Smith, D. I., \& Kirkham, R. W. (1981). Relationship between some personality characteristics and driving record. British Journal of Social Psychology, 20, 229-231.

Spielberg, S. (Director). (1993). Schindler's List (Film). Universal City: Universal Pictures. Spielberger, C. D. (1988). State-trait anger expression inventory. Odessa, FL: Psychological Assessment Resources.

Steffgen, G., Recchia, S., \& Ludewig, J. L. (2008). Deffenbacher driving anger scale: Psychometric properties of a German version. International Journal of Psychology, 43 (3/4). (pp. 20-25) Berlin, Germany: XXIX International Congress of Psychology (07.2008).

Stephens, A. N., \& Groeger, J. A. (2009). Situational specificity of trait influences on drivers' evaluations and driving behavior. Transportation Research Part F, 12(1), 29-39. 
Stradling, S. G., \& Parker, D. (1997). Extending the theory of planned behavior: The role of personal norm, instrumental beliefs, and affective beliefs in predicting driving violations. In J. A. Rothengatter, \& E. Carbonell (Eds.), Traffic and transport psychology: Theory and application (pp. 367-374). Amsterdam: Pergamon.

Sümer, N. (2003). Personality and behavioral predictors of traffic accidents: testing a contextual mediated model. Accident Analysis and Prevention, 35, 949-964.

Taubman - Ben-Ari, O., Mikulincer, M., \& Gillath, O. (2004). The multidimensional driving style inventory-Scale construct and validation. Accident Analysis and Prevention, $36,323-332$.

Ulleberg, P. (2002). Personality subtypes of young drivers. Relationship to risk-taking preferences, accident involvement, and response to a traffic safety campaign. Transportation Research Part F, 4, 279-297.

Underwood, G., Chapman, P., Brocklehurst, N., Underwood, J., \& Crundall, D. (2003). Visual attention while driving: Sequences of eye fixations made by experienced and novice drivers. Ergonomics, 46(6), 629-646.

Underwood, G., Chapman, P., Wright, S., \& Crundall, D. (1999). Anger while driving. Transportation Research Part F, 2, 55-68.

Vallerand, R. J. (2008). On the psychology of passion: In search of what makes people's lives most worth living. Canadian Psychology, 49, 1-13.

Westermann, R., Spies, K., Stahl, G., \& Hesse, F. (1996). Relative effectiveness and validity of mood induction procedures: a meta-analysis. European Journal of Social Psychology, 26, 557-580.

Yagil, D. (1998). Gender and age-related differences in attitudes toward traffic laws and traffic violations. Transportation Research Part F, 1(2), 123-135. 